Research Article

\title{
Removal of Pyrethrin from Aqueous Effluents by Adsorptive Micellar Flocculation
}

\author{
Pardon K. Kuipa ${ }^{1,2}$ and Olga Kuipa ${ }^{1}$ \\ ${ }^{1}$ Department of Chemical Engineering, National University of Science and Technology, Bulawayo, Zimbabwe \\ ${ }^{2}$ School of Engineering Sciences and Technology, Chinhoyi University of Technology, Chinhoyi, Zimbabwe \\ Correspondence should be addressed to Pardon K. Kuipa; kuipapardon@yahoo.com
}

Received 27 August 2014; Revised 6 January 2015; Accepted 6 January 2015

Academic Editor: Wenshan Guo

Copyright ( 2015 P. K. Kuipa and O. Kuipa. This is an open access article distributed under the Creative Commons Attribution License, which permits unrestricted use, distribution, and reproduction in any medium, provided the original work is properly cited.

The equilibrium adsorption of pyrethrin onto aggregates formed by the flocculation of micelles of the surfactant sodium dodecyl sulphate (SDS) with aluminium sulphate is reported. The experimental results were analysed using different adsorption isotherms (Langmuir, Freundlich, Redlich-Peterson, Sips, Radke-Prausnitz, Temkin, linear equilibrium, and the Dubin-Radushkevich isotherms). The Freundlich and linear equilibrium isotherms best describe the adsorption of pyrethrin onto SDS micellar flocs, with the Freundlich adsorption constant, $K_{F}$, and the mass distribution coefficient, $K_{D}$, of $64.266\left((\mathrm{mg} / \mathrm{g})(\mathrm{L} / \mathrm{mg})^{1 / n}\right)$ and $119.65 \mathrm{~L} / \mathrm{g}$, respectively. Applicability of the Freundlich adsorption model suggests that heterogeneous surface adsorption affects the adsorption. The mean free energy value estimated using the Dubinin-Radushkevich isotherm was $0.136 \mathrm{~kJ} / \mathrm{mol}$ indicating that physisorption may be predominant in the adsorption process.

\section{Introduction}

Pesticides may cause acute and chronic toxicity problems in aquatic environments and sometimes even entire food chains. There is therefore mounting pressure to minimise, at source, the upstream discharge of pesticides from manufacturing facilities. This requires the use of innovative and efficient methods for the removal and recycling of pesticides from aqueous effluent streams at pesticide manufacturing facilities before discharge into sewers and other receiving water bodies. A promising technology involves the adsorption of small molecules onto micellar aggregates which are formed when $\mathrm{Al}^{3+}$ cations interact with sodium dodecyl sulphate (SDS) micelles to form cylindrical to worm-like aggregates $[1,2]$. These aggregates form quickly and usually integrate all the micellar surfactant into one single floc which may float on top of the solution and can be easily filtered [3]. The aggregate resulting from flocculation adsorbs organic compounds from the solution it forms in [4], allowing the removal of small molecules by filtration instead of expensive membrane separations. Microscopic photography and X-ray diffractometry have shown that the aggregates consist of small fragments of liquid crystal dispersed in an amorphous matrix [5]. Organic pollutants bind to the floc by electrostatic attraction as free ions (e.g., phenoxide and benzoate ions) on spots on the floc with local positive charge [6]. Micellar flocculation may also involve the formation of complexes since large cationic complexes may be expected within the Stern layer due to the high $\mathrm{Al}^{3+}$ concentration [7].

One of the widely used pesticides is pyrethrin which is commonly used in horticulture for pest control and management. Pyrethrin and pyrethroids such as cypermethrin are also routinely intensively used at very low concentration levels (microgram per litre range) and short periods of time (approximately one hour) in finfish and salmon aquaculture to control sea lice $[8,9]$. At high concentration levels pyrethrins are extremely toxic to fish [10]. The release of pyrethrins to the marine environment is suspected to present a definite risk to pelagic and benthic organisms [11]. Prior to their breakdown pyrethrins are toxic to birds, fish, wasps, and other beneficial insects [12]. There is therefore a need to recover pyrethrin from pyrethrin producing industry 
TABLE 1: Dependence of mass of micellar floc generated, residual pyrethrin equilibrium concentration, and equilibrium amount of pyrethrin adsorbed onto micellar floc on the initial concentration of aluminium sulphate and SDS solutions.

\begin{tabular}{|c|c|c|c|}
\hline $\begin{array}{l}\text { Molar concentration of } \\
\text { solutions of aluminium } \\
\text { sulphate (same for the SDS } \\
\text { solution) used for the } \\
\text { generation of micellar flocs }\end{array}$ & $\begin{array}{c}\text { Mass of micellar floc } \\
\text { generated, mg }\end{array}$ & $\begin{array}{l}\text { Residual pyrethrin } \\
\text { equilibrium } \\
\text { concentration, mg/L }\end{array}$ & $\begin{array}{l}\text { Equilibrium amount of } \\
\text { pyrethrin adsorbed onto } \\
\text { micellar floc (calculated } \\
\text { from mass balance), } \mathrm{mg} / \mathrm{g}\end{array}$ \\
\hline 0.01 & 34.02 & 50.1 & 6612.287 \\
\hline 0.02 & 42.53 & 43.6 & 5365.624 \\
\hline 0.03 & 53.16 & 35.1 & 4372.649 \\
\hline 0.04 & 66.45 & 34 & 3506.396 \\
\hline 0.05 & 83.07 & 30.12 & 2828.217 \\
\hline 0.06 & 103.83 & 19.89 & 2312 \\
\hline 0.07 & 129.79 & 15.44 & 1866.708 \\
\hline 0.08 & 162.24 & 9.48 & 1511.711 \\
\hline 0.09 & 202.8 & 9.27 & 1209.887 \\
\hline 0.1 & 253.5 & 8.97 & 968.501 \\
\hline
\end{tabular}

wastewaters before discharge into the marine environment and municipal sewers.

We have investigated the equilibrium adsorption of pyrethrin onto aggregates formed by the flocculation of micelles of the surfactant sodium dodecyl sulphate (SDS) with aluminium sulphate. Eight isotherm models were used to interpret the experimental data.

\section{Materials and Methods}

2.1. Cleaning of Glassware and Plasticware. All glassware was washed with phosphate-free detergent and rinsed with tap water, then rinsed with $10 \%$ hydrochloric acid, and finally rinsed four times with deionised water.

2.2. Reagents. Aluminium sulphate (AR grade), 70\% sodium lauryl sulphate, sodium hydroxide, and hydrochloric acid were purchased from a local supplier, Associated Chemicals Limited, Zimbabwe. Pyrethrin was supplied by Agricura (Pvt) Ltd, Zimbabwe. A color standard solution (500 platinum-cobalt units) was used to standardize the Hach DR/2010 Spectrophotometer. All chemicals were used without further purification.

2.3. Stock Solutions. Stock solutions of the various reagents (surfactant, aluminium sulphate, acid, and alkali) were prepared and kept at $25^{\circ} \mathrm{C}$. Working solutions were made by making the relevant dilutions of the stock solutions with distilled water. A pH value of 3.7 was maintained for all solutions. The $\mathrm{pH}$ was not buffered in order to prevent interference of the buffer system with the flocculation process. All experiments were conducted at ambient temperature $\left(26^{\circ} \mathrm{C}\right)$ which was above the Kraft point for SDS micelles $\left(25^{\circ} \mathrm{C}\right)$ below which the SDS precipitates from solution.
2.4. Flocculation of Micelles and Adsorption of Pyrethrin. Each working solution for aluminium sulphate was initially dosed with $1000 \mathrm{ppm}$ pyrethrin before commencement of the flocculation of micelles. To initiate the flocculation and adsorption process $250 \mathrm{~mL}$ of aluminium sulphate solution of a known concentration doped with 1000 ppm pyrethrin was mixed with an equal volume of surfactant of the same concentration as the aluminium sulphate solution in a $1000 \mathrm{~mL}$ beaker and stirred with a magnetic stirrer at $300 \mathrm{rpm}$. Small portions of the mixture were withdrawn at time intervals, filtered using a $45 \mu \mathrm{m}$ Whatman cellulose nitrate membrane, and analysed for residual pyrethrin using a HACH DR/2010 Spectrophotometer. The amount of pyrethrin adsorbed by the micellar flocs at equilibrium was calculated by mass balance (see Table 1) as

$$
q_{e}=\frac{\left(C_{0}-C_{e}\right) V}{W}
$$

where $C_{0}$ and $C_{e}$ are the initial and equilibrium pyrethrin concentration $(\mathrm{mg} / \mathrm{L}), V$ is the volume of solution (L), and $W$ is the mass of the micellar floc $(\mathrm{g})$.

2.5. Sample Analysis. A HACH DR/2010 Spectrophotometer was used to indirectly measure the concentration of pyrethrin in samples. The HACH method 8025 based on the APHA platinum-cobalt standard method for water, wastewater, and seawater [13] was used to provide indirect measurements of pyrethrin concentrations using a calibrated curve relating PtCo units to pyrethrin concentration. In brief the method entails the determination of color by entering the Hach DR/2010 stored program number of 120 and adjusting the wavelength to $455 \mathrm{~nm}$. The instrument is zeroed with a blank solution and then standardised with a standard solution of known Pt-Co units. After the instrument is standardized it is then used to record Pt-Co units for the different sample 
solutions and converting these Pt-Co units to pyrethrin concentrations using a calibrated curve.

From Table 1 it can be seen that the residual solute concentration decreases with the amount of micellar floc generated.

2.6. Equilibrium Adsorption Isotherms. The experimental results were analysed using different adsorption isotherms (Langmuir, Freundlich, Redlich-Peterson, Sips, RadkePrausnitz, Temkin, linear equilibrium, and the DubinRadushkevich isotherms) [14].

2.7. Langmuir Isotherm. The Langmuir isotherm [15] describes homogeneous monolayer adsorption. It assumes that forces of interaction between adsorbed molecules are negligible and that adsorption sites are energetically equivalent and that no further adsorption takes place once an adsorption site is occupied. The model is represented by

$$
q_{e}=\frac{q_{m} b C_{e}}{1+b C_{e}},
$$

where $q_{e}$ is the amount of solute adsorbed per unit weight of adsorbent at equilibrium ( $\mathrm{mg} / \mathrm{g}), C_{e}$ is the equilibrium concentration of solute in the bulk phase $(\mathrm{mg} / \mathrm{L}), q_{m}$ is the maximum adsorption capacity $(\mathrm{mg} / \mathrm{g})$, and $b$ is a constant related to the free energy of adsorption ( $\mathrm{L} / \mathrm{mg})$.

2.8. Freundlich Isotherm. The Freundlich isotherm model [16] was applied to study the biosorption behavior assuming a heterogeneous adsorption on the adsorbent surface and assumes a logarithmic decrease in the enthalpy of adsorption with an increase in the fraction of occupied sites and its equation is

$$
q_{e}=K_{F} C_{e}^{1 / n} .
$$

The Freundlich constants $K_{F}\left((\mathrm{mg} / \mathrm{g})(\mathrm{L} / \mathrm{mg})^{1 / n}\right)$ and $n$ (dimensionless) are related to adsorption capacity and intensity, respectively.

2.9. Redlich-Peterson Isotherm. The Redlich-Peterson model [17] has features of both the Langmuir and Freundlich isotherms and contains three parameters:

$$
q_{e}=\frac{A C_{e}}{1+B C_{e}^{g}},
$$

where $A, B$, and $g(0<g<1)$ are the isotherm constants.

2.10. Sips or the Langmuir-Freundlich Isotherm. The Sips isotherm [18] is a semiempirical isotherm which reduces to the Freundlich isotherm at high adsorbate concentrations and the Langmuir isotherm at low adsorbate concentrations and its equation is

$$
q_{e}=\frac{q_{m} b_{S} C_{e}^{1 / n_{S}}}{1+b_{S} C_{e}^{1 / n_{S}}} .
$$

2.11. Radke-Prausnitz Isotherm. The Radke-Prausnitz [19] isotherm contains three parameters and reduces to the Langmuir model for $\alpha_{\mathrm{rp}}=1$ and to the Henry's Law for $\alpha_{\mathrm{rp}}=0$ and is represented by the following equation:

$$
q_{e}=\frac{q_{m} b_{\mathrm{rp}} C_{e}}{\left(1+b_{\mathrm{rp}} C_{e}\right)^{\alpha_{\mathrm{rp}}}} .
$$

2.12. Temkin Isotherm. The Temkin isotherm [20] assumes that during the adsorption process the fall in the heat of adsorption is linear rather than logarithmic and is represented by the following equation:

$$
q_{e}=\frac{\mathrm{RT}}{b_{T}} \ln \left(K_{T} C_{e}\right),
$$

where $b_{T}$ indicates the adsorption potential of the adsorbent $(\mathrm{J} / \mathrm{mol})$ and $K_{T}$ is the equilibrium binding constant $(\mathrm{L} / \mathrm{mg})$.

\subsection{Linear Equilibrium Isotherm. Consider}

$$
q_{e}=K_{D} C_{e},
$$

where $K_{D}$ is the mass distribution coefficient, $q_{e}$ is the adsorption capacity $(\mathrm{mg} / \mathrm{g})$, and $C_{e}$ is the pyrethrin concentration at equilibrium ( $\mathrm{mg} / \mathrm{L}$ or $\mathrm{ppm}$ ).

2.14. Dubinin-Radushkevich (D-R) Isotherm. The DubininRadushkevich (D-R) isotherm [21] is a semiempirical model that was developed to describe adsorption in microporous materials based on the Polanyi potential theory of adsorption [22].

The $\mathrm{D}-\mathrm{R}$ model is described as

$$
q_{e}=q_{m} \exp \left(-\beta\left[\mathrm{RT} \ln \left(\frac{C_{e}+1}{C_{e}}\right)\right]^{2}\right),
$$

where $\beta$ is a constant connected with the mean free energy of adsorption per mole of the adsorbate $\left(\mathrm{mol}^{2} \mathrm{~kJ}^{-2}\right)$ and $q_{m}$ is the theoretical saturation capacity $\left(\mathrm{mgg}^{-1}\right)$. The sorption curve is related to the porous structure of the sorbent.

2.15. Results and Discussion. The adsorption isotherms were fitted to the experimental data using the graphics software OriginPro 9.1. The software uses the Levenberg-Marquardt nonlinear curve fitting method $[23,24]$ which uses two minimization methods: the gradient descent method and the Gauss-Newton method. In the gradient descent method, the sum of the squared errors is reduced by updating the parameters in the direction of the greatest reduction of the least squares objective whilst, in the Gauss-Newton method, the sum of the squared errors is reduced by assuming the least squares function is locally quadratic and finding the minimum of the quadratic. The Levenberg-Marquardt method acts like the gradient-descent method when the parameters are far from their optimal value and acts like the Gauss-Newton method when the parameters are close to their optimal value. 
TABLE 2: Summary table of the equilibrium isotherm parameters for the adsorption of pyrethrin onto SDS micellar flocs.

\begin{tabular}{|c|c|c|c|c|c|}
\hline \multirow{3}{*}{$\begin{array}{l}\text { Adsorption isotherm } \\
\text { Langmuir }\end{array}$} & \multicolumn{3}{|c|}{ Isotherm parameters } & \multirow{3}{*}{$\begin{array}{c}\begin{array}{c}\text { Coefficient of } \\
\text { determination, } R^{2}\end{array} \\
0.137\end{array}$} & \multirow{3}{*}{$\begin{array}{c}\text { Chi-square statistic, } \\
\chi^{2} \cdot\left(10^{6}\right) \\
4.186968\end{array}$} \\
\hline & $q_{m}(\mathrm{mg} / \mathrm{g})$ & & & & \\
\hline & 9600 & & & & \\
\hline \multirow{2}{*}{ Freundlich } & $K_{F}\left((\mathrm{mg} / \mathrm{g})(\mathrm{L} / \mathrm{mg})^{1 / n}\right)$ & & & \multirow{2}{*}{0.973} & \multirow{2}{*}{0.130438} \\
\hline & 64.27 & & & & \\
\hline \multirow{2}{*}{ Redlich-Peterson } & $A$ & $B$ & $g$ & \multirow{2}{*}{0.856} & \multirow{2}{*}{0.799945} \\
\hline & 134.93 & 0.08 & 0.42 & & \\
\hline \multirow{2}{*}{ Sips } & $q_{m}(\mathrm{mg} / \mathrm{g})$ & $b_{S}$ & $g=1 / n_{S}$ & \multirow{2}{*}{0.714} & \multirow{2}{*}{1.585489} \\
\hline & 7733.5 & 0.075 & 0.719 & & \\
\hline \multirow{2}{*}{ Radke-Prausnitz } & $q_{m}(\mathrm{mg} / \mathrm{g})$ & $b_{\mathrm{rp}}$ & $\alpha_{\mathrm{rp}}$ & \multirow{2}{*}{0.664} & \multirow{2}{*}{1.863337} \\
\hline & 2026.6 & 0.07 & 0.4 & & \\
\hline \multirow{2}{*}{ Temkin } & $b_{T}(\mathrm{~J} / \mathrm{mol})$ & \multirow{2}{*}{\multicolumn{2}{|c|}{$\begin{array}{c}K_{T}(\mathrm{~L} / \mathrm{mg}) \\
0.139\end{array}$}} & \multirow{2}{*}{0.889} & \multirow{2}{*}{0.536723} \\
\hline & 0.902 & & & & \\
\hline \multirow{2}{*}{ Linear } & & $(\mathrm{L} / \mathrm{g})$ & & \multirow{2}{*}{0.965} & \multirow{2}{*}{0.172125} \\
\hline & & 9.65 & & & \\
\hline \multirow{2}{*}{$\begin{array}{l}\text { Dubinin-Radushkevich } \\
\text { (D-R) }\end{array}$} & $q_{m}(\mathrm{mg} / \mathrm{g})$ & & & \multirow{2}{*}{0.833} & \multirow{2}{*}{0.812780} \\
\hline & 6552 & & & & \\
\hline
\end{tabular}

The adsorption isotherms were not linearised because previously concern has been raised that transformations of nonlinear isotherm equations to linear forms implicitly alter their error structure and may also violate the error variance and normality assumptions of standard least squares [25]. The best isotherm was adjudged as the isotherm with the highest value of the coefficient of determination, $R^{2}$, and the lowest value of the Chi-square statistic, $\chi^{2}$. The value of the Chi-square statistic, $\chi^{2}$, is smaller when data from a model are similar to the experimental data and larger when the model data and the experimental data are dissimilar. The isotherm parameters obtained from the nonlinear curve fitting of experimental data to the different isotherms using OriginPro 9.1 and the corresponding values of the coefficient of determination, $R^{2}$, and the Chi-square statistic, $\chi^{2}$, are presented in Table 2 .

Based on values of the coefficient of determination, $R^{2}$, and the Chi-square statistic, $\chi^{2}$, we note that the Freundlich and linear equilibrium isotherms best describe the adsorption of pyrethrin onto SDS micellar flocs, with the Freundlich adsorption constant, $K_{F}$, and the mass distribution coefficient, $K_{D}$, of $64.27\left((\mathrm{mg} / \mathrm{g})(\mathrm{L} / \mathrm{mg})^{1 / n}\right)$ and 119.65 L/g, respectively. The Temkin, Redlich-Peterson, and the Dubinin-Radushkevich isotherms give a fair description of the adsorption of pyrethrin onto SDS micellar flocs, while the Sips and Radke-Prausnitz isotherms give a satisfactory description of the experimental adsorption data. The Langmuir isotherm is inapplicable to describe the experimental adsorption data. The Dubinin-Radushkevich isotherm was used to estimate the adsorption mean free energy $E(\mathrm{~J} / \mathrm{mol})$ as the sorbate is transferred to the surface of the adsorbent from an infinite distance in the solution. The adsorption mean free energy was calculated from $E=1 / \sqrt{2 \beta}$, so that $E=136.46 \mathrm{~J} / \mathrm{mol}$. The mean free energy value obtained is less than $20 \mathrm{~kJ} / \mathrm{mol}$ indicating a possible predominance of physisorption in the adsorption process [26].

2.16. Gibbs Free Energy of Adsorption. The Gibbs free energy of adsorption was calculated from $\Delta G^{0}=-\mathrm{RT} \ln K_{D}$, where $K_{D}$ is the mass distribution coefficient $\left(K_{D}=q_{e} / C_{e}\right.$, where $q_{e}$ is the adsorption capacity $(\mathrm{mg} / \mathrm{g})$ and $C_{e}$ is the pyrethrin concentration at equilibrium $(\mathrm{mg} / \mathrm{L}$ or $\mathrm{ppm})$ ). Taking the $K_{D}$ value that was obtained from the linear equilibrium isotherm, $\Delta G^{0}=-11.893 \mathrm{~kJ} / \mathrm{mol}$. The negative value of $\Delta G^{0}$ confirms the thermodynamic feasibility of the adsorption process and its spontaneity on SDS micellar flocs.

\section{Conclusions}

The Freundlich and the linear equilibrium isotherms best describe the adsorption of pyrethrin onto SDS micellar flocs with the Freundlich adsorption constant, $K_{F}$, and the distribution coefficient, $K_{D}$, of $64.266\left((\mathrm{mg} / \mathrm{g})(\mathrm{L} / \mathrm{mg})^{1 / n}\right)$ and $119.65 \mathrm{~L} / \mathrm{g}$, respectively. The value of $n$ was 0.8537 , which is between 0 and 10, suggesting relatively strong adsorption of pyrethrin onto the floc. Applicability of the Freundlich adsorption model suggests that heterogeneous surface adsorption affects the adsorption. The mean free energy value estimated using the Dubinin-Radushkevich isotherm was $0.136 \mathrm{~kJ} / \mathrm{mol}$ indicating that physisorption may be predominant in the adsorption process. 


\section{Nomenclature}

\begin{tabular}{|c|c|}
\hline$q_{e}:$ & $\begin{array}{l}\text { The amount of solute adsorbed per unit } \\
\text { weight of adsorbent at equilibrium (mg/g) }\end{array}$ \\
\hline$q_{m}:$ & $\begin{array}{l}\text { The theoretical saturation capacity of the } \\
\text { adsorbent }(\mathrm{mg} / \mathrm{g})\end{array}$ \\
\hline$K_{F}:$ & $\begin{array}{l}\text { Freundlich isotherm adsorption constant, } \\
(\mathrm{mg} / \mathrm{g})(\mathrm{L} / \mathrm{mg})^{1 / n}\end{array}$ \\
\hline$K_{D}:$ & Mass distribution coefficient, L/g \\
\hline$n:$ & A dimensionless constant in the \\
\hline & $\begin{array}{l}\text { Freundlich isotherm related to adsorption } \\
\text { intensity }\end{array}$ \\
\hline SDS: & Sodium dodecyl sulphate \\
\hline$C_{e}:$ & $\begin{array}{l}\text { Pyrethrin concentration at equilibrium } \\
(\mathrm{mg} / \mathrm{L} \text { or } \mathrm{ppm})\end{array}$ \\
\hline$\Delta G^{0}:$ & Gibbs free energy of adsorption, $\mathrm{kJ} / \mathrm{mol}$ \\
\hline$E:$ & Adsorption mean free energy, $\mathrm{J} / \mathrm{mol}$ \\
\hline$\chi^{2}:$ & Chi-square statistic \\
\hline$R^{2}$ : & Coefficient of determination \\
\hline$\beta:$ & $\begin{array}{l}\text { A constant in the Dubinin-Radushkevich } \\
\text { (D-R) isotherm that is connected with the } \\
\text { mean free energy of adsorption per mole } \\
\text { of the adsorbate }\left(\mathrm{mol}^{2} \mathrm{~J}^{2}\right)\end{array}$ \\
\hline$b:$ & $\begin{array}{l}\text { Langmuir isotherm constant related to the } \\
\text { free energy of adsorption }(\mathrm{L} / \mathrm{mg})\end{array}$ \\
\hline a $g:$ & Redlich-Peterson isotherm constants \\
\hline & Sips isotherm constants \\
\hline$\alpha_{\mathrm{rp}}$ and $b_{\mathrm{rp}}:$ & Radke-Prausnitz isotherm constants \\
\hline$b_{T}:$ & $\begin{array}{l}\text { Temkin isotherm adsorption potential of } \\
\text { the adsorbent }(\mathrm{J} / \mathrm{mol})\end{array}$ \\
\hline$K_{T}:$ & $\begin{array}{l}\text { Temkin isotherm equilibrium binding } \\
\text { constant }(\mathrm{L} / \mathrm{mg})\end{array}$ \\
\hline & Universal gas constant $(\mathrm{J} / \mathrm{mol} \cdot \mathrm{K})$ \\
\hline & Temperature (K). \\
\hline
\end{tabular}

\section{Conflict of Interests}

The authors declare that there is no conflict of interests regarding the publication of this paper.

\section{References}

[1] R. F. P. Pereira, A. J. M. Valente, H. D. Burrows, M. L. Ramos, A. C. F. Ribeiro, and V. M. M. Lobo, "Flocculation and micellization of sodium dodecyl sulfate solutions in the presence of aluminium Nitrate: effect of concentration and temperature," Acta Chimica Slovenica, vol. 56, no. 1, pp. 45-52, 2009.

[2] P. Paton-Morales and F. I. Talens-Alesson, "Effect of ionic strength and competitive adsorption of $\mathrm{Na}^{+}$on the flocculation of lauryl sulfate micelles with $\mathrm{Al}^{3+}$," Langmuir, vol. 17, no. 20, pp. 6059-6064, 2001.

[3] F. I. Talens, P. Patón, and S. Gaya, "Micelar flocculation of anionic surfactants," Langmuir, vol. 14, no. 18, pp. 5046-5050, 1998.

[4] M. Porras and F. I. Talens, "Removal of 2,4-d from aqueous solutions by micellar flocculation," Separation Science and Technology, vol. 34, no. 13, pp. 2679-2684, 1999.
[5] M. Porras-Rodriguez and F. I. Talens-Alesson, "Removal of 2,4dichlorophenoxyacetic acid from water by adsorptive micellar flocculation," Environmental Science and Technology, vol. 33, no. 18, pp. 3206-3209, 1999.

[6] F. I. Talens-Alesson, "Binding of pesticide 2,4-D to SDS and AOS micellar flocculates," Colloids and Surfaces A: Physicochemical and Engineering Aspects, vol. 180, no. 1-2, pp. 199-203, 2001.

[7] F. I. Talens-Alesson, S. Anthony, and M. Bryce, "Complexation of organic compounds in the presence of $\mathrm{Al}^{3+}$ during micellar flocculation," Water Research, vol. 38, no. 6, pp. 1477-1483, 2004.

[8] W. Ernst, P. Jackman, K. Doe et al., "Dispersion and toxicity to non-target aquatic organisms of pesticides used to treat sea lice on salmon in net pen enclosures," Marine Pollution Bulletin, vol. 42, no. 6, pp. 433-444, 2001.

[9] J. L. Hart, J. R. M. Thacker, J. C. Braidwood, N. R. Fraser, and J. E. Matthews, "Novel cypermethrin formulation for the control of sea lice on salmon (Salmo salar)," Veterinary Record, vol. 140, no. 7, pp. 179-181, 1997.

[10] M. Haitzer, S. Höss, W. Traunspurger, and C. Steinberg, "Effects of dissolved organic matter (DOM) on the bioconcentration of organic chemicals in aquatic organisms-a review," Chemosphere, vol. 37, no. 7, pp. 1335-1362, 1998.

[11] Federal/Provincial/Territorial Advisory Committee on Canada's National Programme of Action for the Protection of the Marine Environment from Land based Activities, Canada's National Programme of Action for the Protection of the Marine Environment from Land based Activities (NPA), chapter 7, NPA Secretariat, Environment Canada, Hull, Canada, 2000.

[12] European Food Safety Authority (EFSA), "Peer review of the pesticide risk assessment of the active substance pyrethrins," EFSA Journal, vol. 11, no. 1, article 3032, 2013.

[13] Hach Company, Water Analysis Handbook, Hach Company, Loveland, Colo, USA, 3rd edition, 1997.

[14] D. G. Kinniburgh, "General purpose adsorption isotherms," Environmental Science and Technology, vol. 20, no. 9, pp. 895904, 1986.

[15] I. Langmuir, "The constitution and fundamental properties of solids and liquids. Part I. Solids," The Journal of the American Chemical Society, vol. 38, no. 2, pp. 2221-2295, 1916.

[16] H. M. F. Freundlich, "Uber die adsorption in losungen," Zeitschrift für Physikalische Chemie, vol. 57, pp. 385-470, 1906.

[17] O. Redlich and D. L. Peterson, "A useful adsorption isotherm," The Journal of Physical Chemistry, vol. 63, no. 6, p. 1024, 1959.

[18] R. Sips, "On the structure of a catalyst surface," The Journal of Chemical Physics, vol. 16, no. 5, pp. 490-495, 1948.

[19] C. J. Radke and J. M. Prausnitz, "Adsorption of organic solutes from dilute aqueous solution on activated carbon," Industrial and Engineering Chemistry Fundamentals, vol. 11, no. 4, pp. 445451, 1972.

[20] M. J. Temkin and V. Pyzhev, "Recent modifications to Langmuir isotherms," Acta Physicochimica USSR, vol. 12, pp. 217-222, 1940.

[21] M. M. Dubinin, "The potential theory of adsorption of gases and vapors for adsorbents with energetically nonuniform surfaces," Chemical Reviews, vol. 60, no. 2, pp. 235-266, 1960.

[22] M. Polanyi, "Theories of the adsorption of gases: a general survey and some additional remarks," Transactions of the Faraday Society, vol. 28, pp. 316-321, 1932.

[23] K. Levenberg, "A method for the solution of certain nonlinear problems in least squares," The Quarterly of Applied Mathematics, vol. 2, pp. 164-168, 1944. 
[24] D. W. Marquardt, "An algorithm for least-squares estimation of nonlinear parameters," Journal of the Society for Industrial and Applied Mathematics, vol. 11, no. 2, pp. 431-441, 1963.

[25] Y. S. Ho, J. F. Porter, and G. McKay, "Equilibrium isotherm studies for the sorption of divalent metal ions onto peat: copper, nickel and lead single component systems," Water, Air, and Soil Pollution, vol. 141, no. 1-4, pp. 1-33, 2002.

[26] P. Atkins, Physical Chemistry, Oxford University Press, London, UK, 6th edition, 1999. 

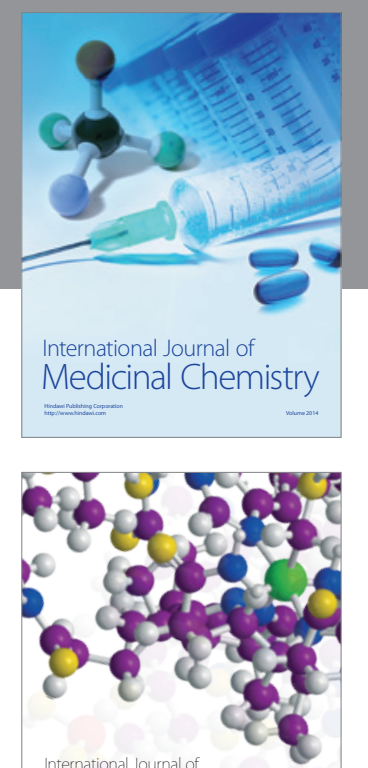

\section{Carbohydrate} Chemistry

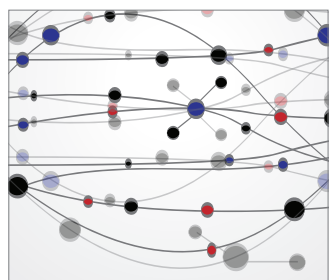

The Scientific World Journal
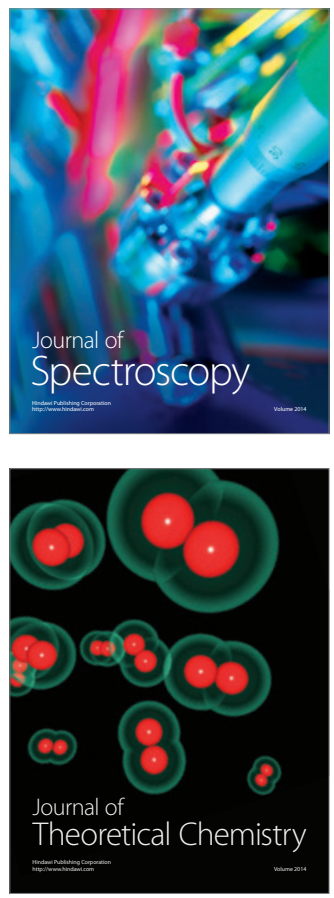
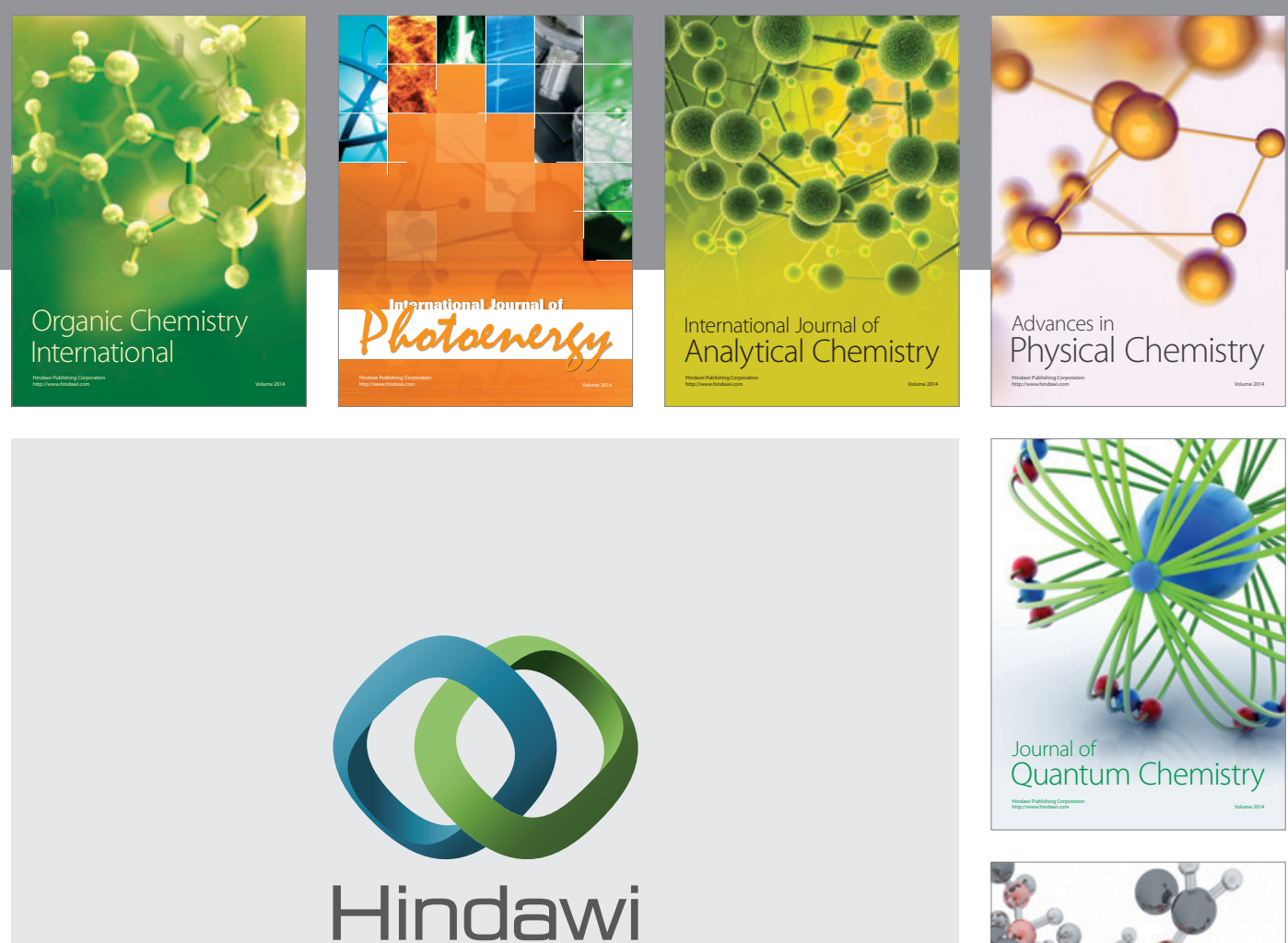

Submit your manuscripts at

http://www.hindawi.com

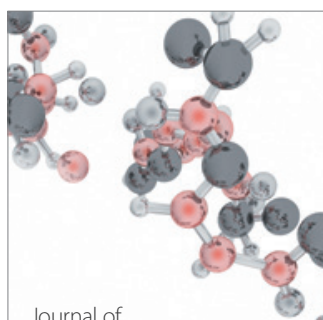

Analytical Methods

in Chemistry

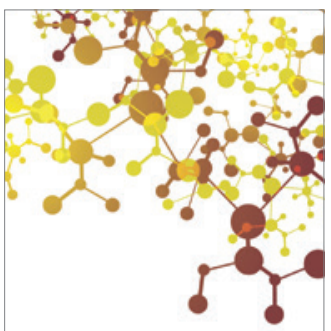

Journal of

Applied Chemistry

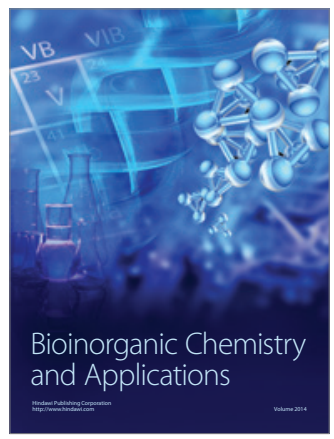

Inorganic Chemistry
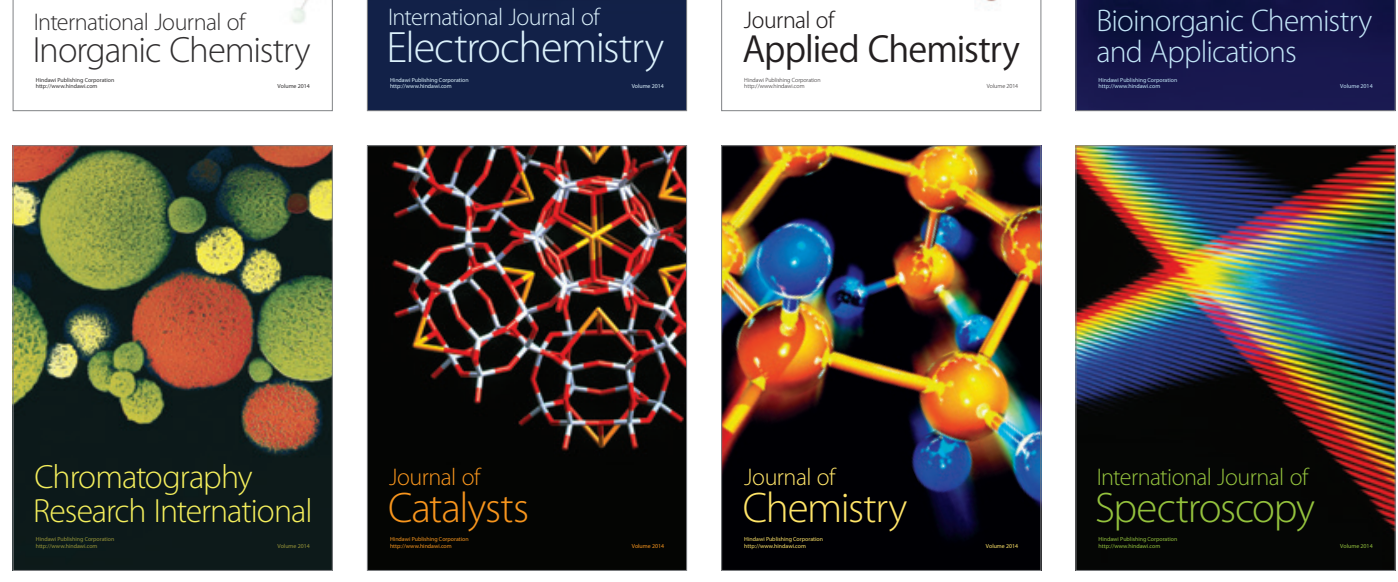